\section{CURIOUS FIREBALL}

SIR J. C. COWELL has kindly sent the accompanying $S$ sketch of a fireinall which he saw fall "one mile east of Slough at 2.8 P.M. on November 30 last," during the short and sharp thunderstorm which passed over North Hants and East Berks. "The flash fell about $x 50$ yards south of the G. W. Railway, and terminated with the explosion of a fireball, which seemed (it was daylight) about I $2 \mathrm{ft}$, in diameter. The explosion was similar to that of a

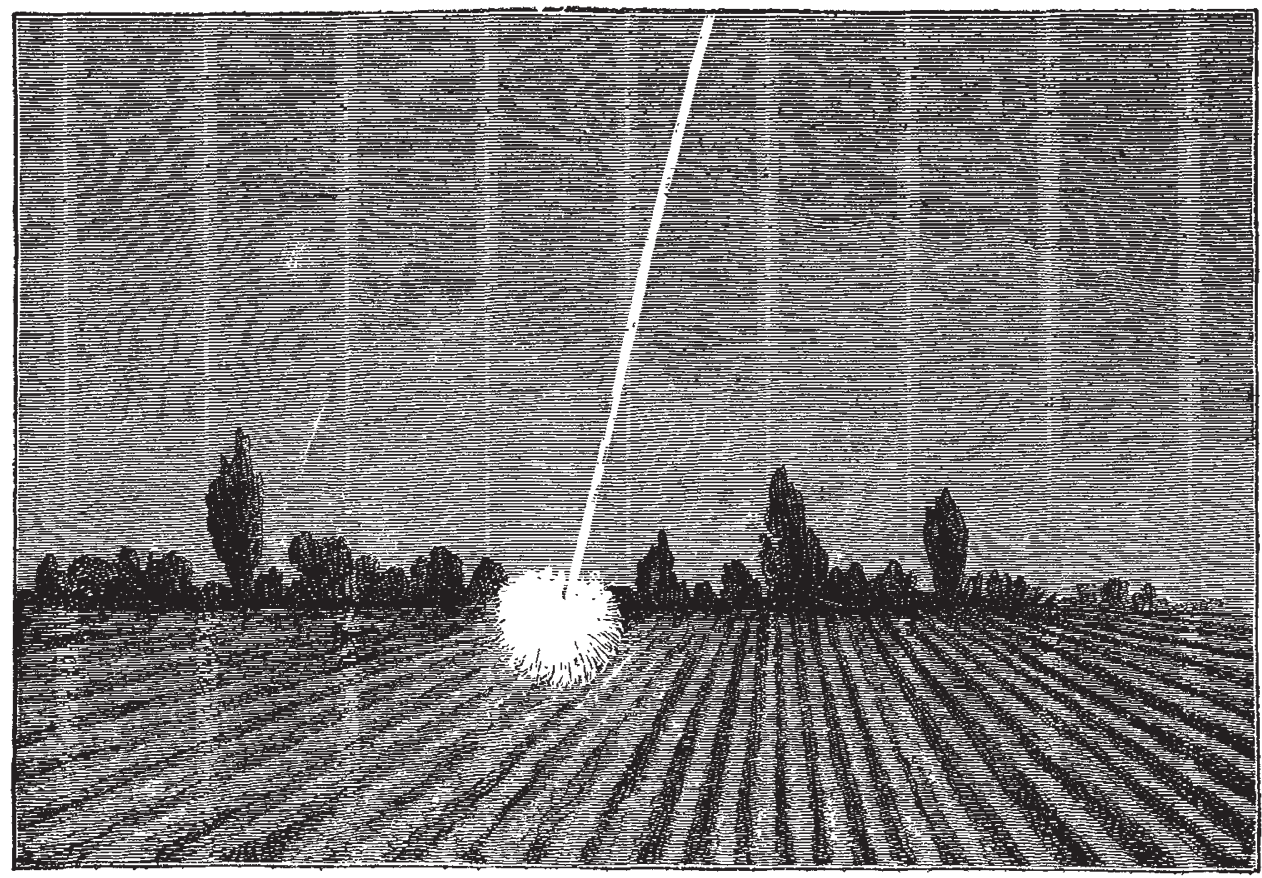

Fire-ball seen near Slough, Nov. 30.

heavy gun when fired, and the ball appeared to burst on the flash reaching the ground, exactly like a well-timed shell."

\section{RECENT DISCOVERIES IN THE GREAT P YRA MID OF EGYPT-ANCIENT EGYPTIAN WEIGHT}

$\mathrm{I}$ addition to the casing-stone of the Great Pyramid, mentioned in NATURE of Nov. 28 as having recently arrived in England, Mr. Dixon has also sent the following asticles found by him in newly-opened passages of the Great Pyramid :-

I. A small double hook of bronze, with rivetted pins for attaching it to a handle.

2. A small rectangular rod of cedar, broken at one end, and some fragments.

3. A granite ball, supposed to be an ancient weight.

Not the least curious and interesting part of Mr. Dixon's discovery is that of the passages or channels in which these articles were found. The publications of Prof: Piazzi Smyth and others have made us acquainted with the position of the King's Chamber in the central part of the Great Pyramid, with its coffer, and ascending passages leading from it ; as well as with that of the Queen's Chamber, with its walls formed of the finest and whitest limestones, highly worked, this chamber having but one entrance by the horizontal passage leading to it, and its purpose proving such an enigma to our Astronomer Royal for Scotland. In examining the walls of the Queen's Chamber, with the view of ascertaining whether there existed any air channels communicating with it, similar to those of the King's Chamber, discovered by Colonel Howard Vyse in 1837 , Mr. Dixon found, by inserting a wire between the joints of the masor ry of the south wall, that there was a hollow space behind this part of the south wall.

On drilling a hole through the upper part of the second stone from the floor, about midway between the east and west walls, at five inches depth a cavity was found, and the hole was then enlarged sufficiently to admit a man's head and arm with a lighted candle. A passage or chañnel was thus disclosed, nearly nine inches by eight in rectangular section, which had been carefully cut through the stone to within five inches of the face of the wall in the Queen's Chamber, the end surface being accurately squared and finished off. This channel extended in a horizontal direction for the length of seven feet, and then ascended at an angle of about $32^{\circ}$. The sides of the channel were found to be blackened with smoke, like the walls of the Queen's Chamber, and it was thought that a slight draught was perceptible. The bronze hook was discovered lying amongst a small heap of débris at the bottom of the ascending channel.

This channel on the south side of the Queen's Chamber having been discovered, which appeared to be precisely similar to the air channel of the King's Chamber, and to ascend at the same angle, an attempt was naturally made to find a corresponding channel behind the wall on the north side of the Queen's Chamber, though no indication of any such channel presented itself on the surface of the wall. After using measuring rods to mark a spot exactly opposite to the drilled hole on the south wall, a hole was bored in the north wall, and a similar cavity was at once found. By enlarging the opening as before, a second channel was discovered of the same dimensions, and which, after proceeding horizontally for seven feet, also ascended at an angle of about $32^{\circ}$.

The surface of the stone in the channel on the north side appeared to be as clean as when originally cut, and
the cement of the joints was perfectly white. 
a handful or two of debris of lime at the bottom of the ascending portion of the channel, which had apparently fallen during the construction, and amongst this débris were found the granite ball and the piece of wooden rod and framments. There was no indication of any draught in this north channel, and indeed the untarnished

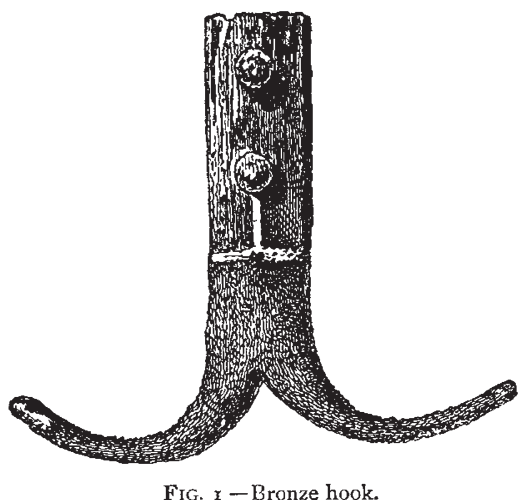

state of its walls, when opened, afforded the strongest proof that it was securely closed up. Hence the certain antiquity of the granite ball and wooden rod.
No trace of any outlet or opening to either channel could be discovered on the exterior of the Pyramid. Experiments were made by firing a pistol in the ventilating channel of the King's Chamber, at the same time holding a lighted candle at the opening of the channel in the Queen's Chamber, and vice versâ, with the view of ascertaining if there was any communication between them ; but no such connection could be perceived.

Some borings were also made in the stones of the east and west walls of the Oueen's Chamber, but without finding any cavity behind them. The discovery of these channels, which may be called "Dixon's Channels," in no way tends as yet to solve the enigma of the Queen's Chamber, but rather to increase the difficulties of the solution. The mystery of the interior of the Great Pyramid remains still to be fathomed.

I. The bronze hook (Fig. I) is covered with green oxide of copper, but a small notch recently made in it with a file shows it to be of bronze or gun metal. The two pins have a large rivetted head on both sides. Its length is $I .8$ inch, and the distance from the two extremities of the hooks is two inches. With a wooden handle attached by the two pins, it may have been used as a tool of some kind. It is probably the most ancient specimen of bronze now existing.

2. The fragment of the cedar rod (Fig. 2) is 5 inches in length, with a rectangular section of $0^{\circ} 5$ inch by $0_{4}^{\circ}$ inch. Its sides are not accurately planed, and they bear parallel lines like file marks. It may possibly have formed

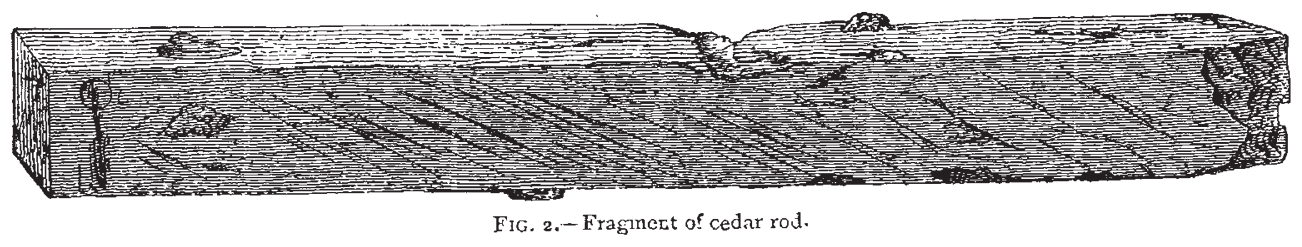

part of a measure of length; or it may have been part of the handle of the bronze hook, the remaining fragments showing that it must have been at least 3 inches longer. Tkere are no lines or marks upon it indicating a measure of length.

3. The gray granite ball (Fig. 3) has a mean diameter of $2 \frac{3}{4}$ inches. Its form is that of an orange squeezed somewhat out of its natural shape. Its greatest diameter is 2.88 inches, and its least 2.65 inches. Its surface is uneven, and shows no mark of any tool, and it presents the appearance of having been roughly rounded by being shaken in a vessel with other stones. On the surface when found were several white spots of lime or plaster. In this condition it has been accurately weighed in the Standards Department, and its weight was found to be $8,324.97$ grains. After this weighing, the lime or plaster was carefully removed and preserved, when the weight of the granite ball was found to be $8,322^{\circ} 4$ grains, equivalent to 539.282 metric grammes.

It next remained for consideration how far the weight of this granite ball, which must have remained undisturbed in the Great Pryamid for not much less than 4000 years (the date more generally ascribed to the construction of the Great Pyramid, being 2200 B.c.) agrees with any of the ancient Egyptian weights.

According to Dr. Arbuthnot, as quoted by Dr. Young in his article "Weights" in the Enclycopxedia Britannica, the ancient Egyptian Mina weighed 8,236 English grains, or $532^{\circ} 683$ grammes, thus differing not very much from that of the granite ball. But later authorities do not agree with this weight of the Egyptian Mina. According to them the ancient weight nearest to that of the ball is the Babylonian Mina $=544^{\circ} 5$ grammes.

Prof. Miller, in his account of the New Standard Pound, (p. 755) has shown that in frequent instances, the Imperial modern pound, or unit of weight, differs very little from, and is therefore derived from, the ancient Egyptian

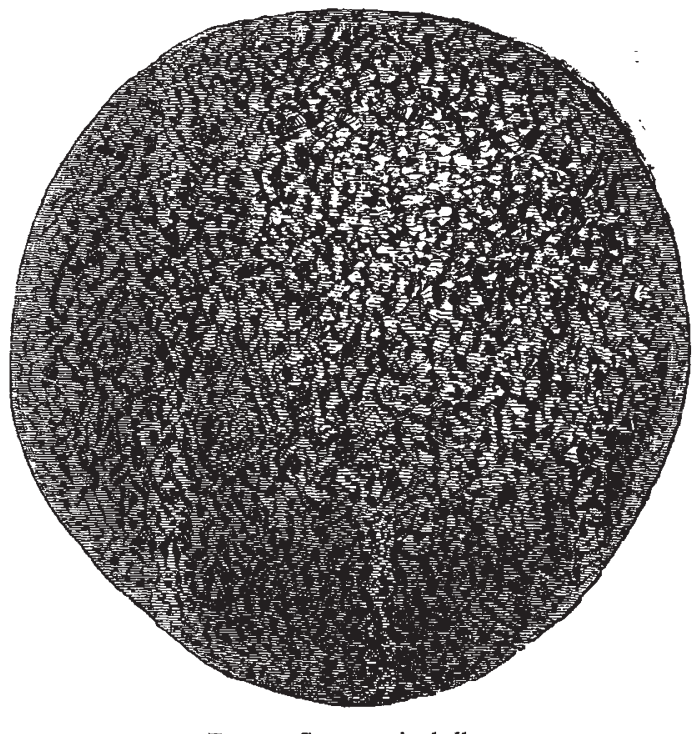

FIG. 3.-Gray granite ball.

Mina. It may therefore be interesting to pursue the inquiry more closely.

Perhaps the fullest account of ancient "weights and 
measures is to be found in Don. V. Quiepo's Essai sur les systèmes Mitriques des Anciens Peuples (Paris, 1849) which contains much curious and instructive information on the subject, as well as reference to the best existing authorities.

It would appear that very little is known of the system of Egyptian weights previous to the time of the Ptolemies, the first of whom, Ptolemy Lagus, one of the Generals of Alexander the Great, became King of Egypt, 323 B.C. It is also stated that there is no certainty of the existence of any Egyptian weights which were constructed much before that period. But there is evidence that the ancient system was continued by Ptolemy Lagus, when he reformed the Egyptian weights and measures, although it can hardly be imagined that the Egyptian unit of weight remained unaltered for nearly twenty centuries. The earliest systems of weights and measures not only in Egypt, but in Assyria and Phœnicia, were based on the same principle, that of the length of the cubit and of the foot, which were to each other in the proportion of 3 to 2 . The Cubit was the unit of length measure; the measure of a cubic foot of water (Metretes) was the unit of capacity both for liquids and dry goods; the Talent or the weight of a cubic foot of water, was the larger unit of weight, whilst the Mina, either the 5oth, 6oth, or Iooth part of the talent, and the Sicle or Shekel, either the 4oth, 6oth, or rooth part of the Mina, were the smaller units of weight.

The great Alexandrian Talent of Ptolemy Lagus has been shown to have weighed 42.480 kilogrammes. The 6 oth part was the Mina $=708$ grammes, the 5 oth part of which was the Didrachma or Shekel $=$ r4 grammes. This was also the weight of the Jewish Shekel of the Sanctuary, often mentioned in the Old Testament.

Another Talent was also in use which was half the weight of the Great Talent, its Mina weighed 354 grammes, and the Drachma 3.54 grammes. Don. V. Quiepo mentions the fact of there being now in the Lourre tiro ancient Egyptian standard weights of roughly rounded stone, weighing $35^{\circ} 16$, and 176.75 grammes respectively, evidently Mina and half-mina weights, as well as a similarly rounded stone weight, marked with six lines of hieroglyphics, found to weigh 4I4 grammes; this is thought to be an Attic Mina, known to be used in Egypt in the time of the Ptolemies, the weight of which was 425 grammes. There are also in the Louvre three ancient Egyptian bronze weights, weighing respectively 3.57 , 3.56 , and 3.62 grammes, evidently drachma weights.

Let us now endeavour to ascertain the length of the Cubit at the period of the construction of the great Pyramid, and thence deduce the weight of the ancient Egyptian Mina. In this computation it will be desirable to make use of metric weight and measure, from their great convenience in expressing the measure of length, capacity, and weight, by the same significant figures. The weight of water in relation to its bulk will thus be taken as determined for the metric system, that is to say, of pure water at its maximum density.

The latest and most satisfactory information on the length of the Cubit during the construction of the Great Pyramid, is to be met with in the Notes of Sir Henry James, published in 1866 , with reference to the measurements made in the previous year by Ordnance Surveyors.

Herodotus, writing 450 B.C., says that "the Egyptian Cubit is equal to that of Samos" that is to say, to the Greek Cubit.

Now the length of the Greek Cubit has been satisfactorily ascertained from a recent measurement of the Hecatompedon of the Parthenon of Athens, being the platform on which the columns stand,and the exact length of Ioo feet. The Greek foot has thus been found to be equal to $12 \cdot 16032$ English inches, and, adding half its length $(6.08016$ inches), shows the length of the Greek cubit to be 18.2405 inches. This, therefore, was the length of the Greek cubit 2,320 years ago, and, according to Herodotus, also the length of the Egyptian cubit.

But it has been considered by the greatest authorities that the length of the Egyptian cubit at the period of the construction of the Great Pyramid may be ascertained from the dimensions of the Pyramid itself.

Sir Isaac Newton, in his celebrated "Dissertation on Cubits," says that it is very probable that at first the Measure of the Great Pyramid was determined by some round number of Egyptian cubits.

According to the measurement of the four sides of the base of the Great Pyramid, as it must have stood when complete with its casing stones, the mean length of each side, as measured by Mr. Inglis in I865 (Prof. Piazzi Smyth's "The Great Pyramid," vol. ii. p. I34), and by the Ordnance Surveyors in 1868, was 9, I 20 English inches, or 760 feet.

But 9,120 inches are precisely equivalent to 500 Egyptian or Greek cubits of 18.2415 inches.

From the measurements by Col. Vyse and Mr. Perring of the second and third Pyramids it would also appear that the same unit of length was used, the base of the second pyramid being a square of 700 Egyptian feet, and that of the third 350 Egyptian feet. Assuming, therefore, 500 ancient Egyptian cubits, or 750 Egyptian feet, to have been equal to 760 English feet, the Egyptian foot equals I'OI 3 English foot, or 30.86 centimetres.

The Talent derived from the weight of water contained in this Egyptian foot would be equal to $29^{*} 3892$ kilogrammes, and the Mina, its fiftieth part, would equal $587^{\circ} 76$ grammes. These weights agree very nearly with those of the ancient Phœnician weights, used as commercial weights in Egypt in the time of the Pharaohsviz., the Kikkar (equal to $29^{\circ} 360$ kilogrammes) and the Mina of the market (equal to $587^{\circ} 213$ grammes), as shown by Don V. Quiepo.

This common or profane cubit (equal to $18.24 \times 5$ English inches, or $46^{\circ} 3 \mathrm{I} 9$ centimetres) is to be distinguished from the sacred cubit or culitit of Mempliss, as it has been termed by Sir Isaac Newton, equal to 20.528 inches, or 52.379 centimetres, which was derived by him from the interior dimensions of the Pyramid, and more particularly from the length and breadth of the King's Chamber, taken to be twenty and ten cubits respectively. The cubits cut on the Nilometer at Cairo now measure 20.699 English inches, or 52.559 centimetres, leaving no doubt of their being intended to be cubits of Memphis.

The double or Royal cubit of Memphis would thus, according to Isaac Newton, be $4 \mathrm{r}^{\circ} 256$ English inches. An ancient Royal cubit found at Cairath, is now in the British Museum, the length of which has been found to be $4 \mathrm{I}^{\circ} 39^{8}$ inches, or $105^{\circ} \mathrm{I}$ I 8 centimetres, being exactly double the Nilometer cubit. It is divided into fourteen palms (of 2:956 inches, or 75 millimetres), and the palm into four digits (of 0.739 inches, or 18.7 millimetres). The length of its cubit differs only $0^{\circ} 07$ I inches from the length as deduced by Sir Isaac Newton.

The Chaldæo-Hebraic, or sacred Jewish Cubit was taken by Sir Isaac Newton to be $\frac{1}{5}$ longer than the cubit of Memphis, and thus to be equal to $24 \cdot 84$ English inches. This was the first result of his investigations, and it agrees with an actual measurement by Mersennus of 24.83 inches. This cubit was probably divided into six palms of 4.I4 inches, ten of which would be very nearly equal to a Royal Cubit of Memphis, in terms of which the interior dimensions of the Great Pyramid appear to have beer. set out, as well as those of the second and third Pyramids.

It is very probable that the ancient cubit of Memphis, several of which have been found in buildings, was used in the measurement of buildings, whilst the cubit of 18.24 inches was employed for measuring land only.

The Egyptian foot corresponding with the cubit of Memphis, of 20.628 inches, derived from the Great Pyra- 
mid, would be equal to 13752 English inches, or 1146 feet, and to $34^{\circ} 9^{19}$ centimetres. The weight of water contained in such a cuist foot would be 42.578 kilogrammes, thus closely approximating to the weight of the great Alexandrian Talent in the time of the Ptolemies.

These investigations show that it is quite possible that the granite ball now found may have been an ancient Egyptian Mina weight. It has been suggested that it may have been used as a hammer, as it is known that at early periods stone balls were so used; and indeed, a part of the surface of the ball looks as if some of the granite had been knocked away. But even if so used, it by no means follows that it was not originally intended as a weight, for evidence was given before the Standard Commission by our Local Inspectors of Weights and Measures that brass standard weights not unfrequently show evident marks of having been used as hammers. If a portion of the weight had thus been knocked off, the difference between its present weight of $539^{\circ} 282$ grammes, and the weight of the ancient Egyptian commercial Mina of 587 grammes, might be readily accounted for. Assuming the granite to have been really an Egyptian weight, it must be the most ancient weight now existing.

Some words may be added, in conclusion, upon the possibility of ascertaining the unit of ancient Egyptian weight from the internal dimensions of the coffer in the King's Chamber of the Great Pyramid, this coffer of red granite having been often considered to be a standard measure of capacity. Its internal dimensions were accurately measured by Prof. Piazi Smyth, and were determined as follows :-

$$
\begin{aligned}
\text { Mean length } & =77^{\circ} 93 \text { inches } \\
, \quad \text { breadth } & =26^{\circ} 73, \\
, \text { depth } & =34.34,
\end{aligned}
$$

The capacity of the coffer is thus equal to $7 \mathrm{I}^{\circ} 532$ cubic inches, or $41 \cdot 396$ cubit feet, equivalent to II 7 X'129 cubic decimetres, showing its contents of water to weigh I 71.129 kilogrammes, equivalent to $258 \mathrm{r} \cdot 89$ avoirdupois pounds; or, if the English weight of the cubic foot of water at its ordinary temperature, viz. 62.32I lbs., be taken, the contents of the water would weigh $2579^{\circ} 84 \mathrm{clbs}$. This result is in no way commensurable with the unit of weight derived from either of the before-mentioned ancient units of linear length, nor do the measurements of the coffer agree with any round number of such units of length. The coffer thus fails to afford an indication to the unit of ancient Egyptian weight, according to this mode of computation.

H. W. C.

\section{THE DIATHERMANCYOF FLAME}

$\mathrm{T} \mathrm{T}$ will be seen by the following exposition that the criticism contained in the article written by W. Mattieu Williams, published in NATURE, vol. vi. pp. 506, 507, is based on wrong assumptions.

The apparatus illustrated in NATURE, vol. vi. p. 458 , was constructed for the purpose of determining certain questions connected with the passage of solar rays through flame. Incidentally it admits of being employed for ascertaining the retardation suffered by artificial radiant heat in passing through a series of flames. The table before published contains the result of a recent preliminary experiment instituted to show that the transparency of flame is too imperfect to warrant the important inference which Père Secchi has drawn from Père Provenzali's experiment with a series of small flames.

The assumption that the experiment published in NATURE was intended to settle the abstract question of diathermancy is wholly gratuitous. Probably there is no problem within the range of experimental philosophy more difficult, or requiring more time, patience, and delicate instruments for its solution, than the diathermancy of flame.
Regarding the supposed imperfections of the apparatus under consideration, the following statement will suffice : -I. Mr. Williams asserts that the main pipe to which the burners are applied is too small to afford a full supply of gas. The internal diameter of this pipe is 0.75 ins. = 0.4417 square ins. Now, it has been long established in practice that an opening of 0.0037 sq. ins. is capable of discharging six cubic feet of gas per hour, under ordinary pressure. Mr. Williams's seventeen burners consumed, agreeably to his statement, five cubic feet of gas per hour. The sectional area of the supply pipe, imagined to be too small, is therefore 0.447 = II9 times greater than the area of an opening capable of discharging more gas in a given time than the quantity consumed by the seventeen burners employed by the author of "The Fuel of the Sun." 2. The assumption that the prolongation of the axis of the conical chamber passes through " much of the blue. portion of the flame" is groundless. The distance of the gas-pipe from the conical vessel, during the experiment, was so adjusted that the prolongation of the axis of the latter passed through the flames at the point of greatest intensity. But, had this adjustment been neglected, the radiant heat, acting on the thermometer, would not have suffered any diminution, since the intensity transmitted depends solely on the extent of the ignited portion of the flame. The criticism regarding the position of the axis of the instrument has therefore no bearing on the question at issue. 3. Mr. Williams's disquisition relating to the retardines influence of the vapour contained in flames, so far from establishing the perfect diathermancy assumed by Père Secchi, proves, if we admit the soundness of the reasoning, that radiant heat does not pass freely through flame; when arranged in the manner adopted by Père Provenzali. It will be well to observe that the plan of igniting one flame at a time in order to ascertain the radiant power transmitted by each was resorted to with a view of deciding the question by a similar method to that adopted by the Itailian physicists.

The apparatus contrived by Mr. Williams for determining the diathermancy of flame, as described by bimself, is exceedingly faulty, the temperature it records being that produced by heat received from several sources. The radiant heat transmitted to the bulb of the thermometer by the flames, acting conjointly with the unknown degres of heat imparted by the surrounding medium, it will be evident that Mr. Williams's device is worthless as an indicator of radiant intensity. His thermometer, agreeably to the published table, indicated $19^{\circ} \mathrm{C}$. when exposed to a single flame, and $53^{\circ} \mathrm{C}$. when all the flames were ignited; but no information is afforded regarding the temperature of the enclosure (an imperfectly polished vessel) nor was the temperature of the air surrounding the bulb of the thermometer ascertained during the experiment. It is scarcely necessary to explain that in the absence of any indication of the temperature of the air surrounding the bulb of the thermometer, and the temperature of the vessel which radiates towards the bulb, the radiant intensity transmitted by the several flames cannot be determined. Again, Mr. Williams's table, as before stated, shows that the thermometer indicated $19^{\circ} \mathrm{C}$. under the effect of the radiation of one flame, but this temperature being the joint result of heat radiated towards the bulb by the enclosure, and heat communicated by convection of the air surrounding it, together with the radiant heat transmitted by the flame, the temperature due to the radiation of the latter, viz, the true radiant intensity, cannot be established. Experimenters possessing necessary experience are aware that a thermometer of proper form exposed to radiant heat of moderate intensity requires from twenty to twentyfive minutes before the mercurial column becomes so nearly stationary that the indication may be safely recorded ; hence, owing to the close proximity o the flames, 